\title{
international news
}

ThE UK's National Radiological Protection Board is setting up a comprehensive register of all UK radiation workers. Although radiation dose records are already kept by individual employers in the radiation industries, these data will, for the first time, be collected together in the register; epidemiological studies of radiation workers will then be much easier to carry out than they have been in the past.

The success of the register will depend on the cooperation of the different sectors of industry and of the UK Office of Population Census and Surveys (OPCS) which will play a vital part in tracing the medical histories and causes of death of those registered. Discussions are still in progress with the OPCS and with employers and trade unions, so final plans are not yet complete, but the NRPB is optimistic about the possibilities. It hopes to be able to make a start within a few months by putting plutonium workers on the register, and then to follow this up by adding all other radiation workers to its files. The register will record internal exposure from ingested radioactive substances as well as external exposure.

A compelling reason for setting up such a register, according to the NRPB, is that it should help to establish the long term effects of low doses

THE vulnerability of the research teams attached to the smaller drug companies was made painfully obvious recently to the research staff of Aspro-Nicholas, the UK subsidiary of the Australian pharmaceutical concern. The entire research staff of around 170 scientists and technicians at the Nicholas Research Institute at Slough were told that they had lost their jobs as the company had decided to close down its research effort completely. Although Nicholas does development work and has manufacturing interests in several countries, all basic new product research has been concentrated in the UK and will now cease. A small unit in Australia which carries out long-term toxicology studies will stifl remain in being.

Although possible cuts in the research budget and even a few redundancies had been envisaged by the staff as a result of the prevailing economic conditions, the whole-

\section{Register for UK radiation workers \\ from Peter Goodwin}

of radiation. Although there is every reason to believe, on the basis of experience in industries throughout the world which are involved with radiation, that the present permissible dose levels for radiation workers are safe, it has been difficult to establish this with certainty in the absence of a comprehensive record. Individual radiation workers move from job to job, and also take jobs in industries not concerned with radiation, so dose records are often incomplete. The permissible dose levels accepted at present are mostly calculated by extrapolation from studies made among such populations as the Japanese exposed to radiation from the Hiroshima and Nagasaki nuclear bombs and those exposed to radiation for medical purposes. But as such populations were subjected to far higher doses than are experienced in occupational situations, there is always some doubt as to whether the extrapolation is reliable.

The register is planned to be both

sale closure of the laboratories came as a complete shock to those involved. The reasons given by the company were the rising costs of research and the decreasing chances of a significant breakthrough. About 120 of the staff have been given one month's notice and others have been invited to stay on for a few months to wind up projects.

The view that investment in pharmaceutical research is now yielding a steadily diminishing return is to some extent supported by surveys from the United States. In 1959, 63 new drugs were put on the market there; in the early 1970s, in spite of a trebling in research funds, an average of only 15 new drugs each year appeared between 1971 and 1973.

This is small comfort to the staff of Nicholas, however, who felt that they had several promising lines of research which could have started to show a return during the next few years. The research effort at retrospective and prospective. Retrospective epidemiological studies can be difficult to carry out because employers do not normally keep track of their employees after their employment has ended. Also employees' National Health Service (NHS) Numbers are of ten lacking on the company records. A further complication arises from the 'notional dose' phenomenon: the practice of some companies of estimating employees' doses in the absence of genuine records. As 'notional doses' are generally high, to give a margin of safety, it is possible that retrospective studies can give the impression that a relatively high occupational dose is less harmful than it actually is. In svite of these difficulties, says the NRPB, the register should greatly facilitate retrospective investigations of posuble radiation effects. Prospectively, it will ensure that all future dose records contain all relevant information, such as the employee's NHS number, so that his death certificate can ultimately be located, as well as date of birth, address, and other facts relevant to tracing his medical history. But as possible carcinogenic effects of low dose radiation are expected only to show up in the very long term, the prospective records are unlikely to be useful for assessing the safety of dose levels for many years, perhaps decades.

Nicholas has only been going at a significant level for about six years, a relatively short time in applied pharmaceutical research. Research was in progress into analgesics, anti-inflammatory agents, drugs affecting the central nervous system such as anti-depressants and minor tranquillisers, and cardiovascular drugs. Several compounds had reached the drug candidate stage. Nicholas was also evaluating several compounds initially developed in university laboratories.

A spokesman for the Association of the British Pharmaceutical Industry said that the association had been issuing warnings for some time that the high cost of research and the increase in time needed to bring a new product on to the market, together with a decline in profitability of the industry generally, has created a situation in which the research and development needed to produce new medicines is being placed in jeopardy. 